\title{
Science of Business \& Information Systems Engineering
}

\author{
DOI 10.1007/s12599-010-0123-7
}

\section{The Authors}

\author{
Prof. Dr. Robert Winter ( $\varangle)$ \\ Institute of Information \\ Management \\ University of St. Gallen \\ Müller-Friedberg-Strasse 8 \\ 9000 St. Gallen \\ Switzerland \\ Robert.Winter@unisg.ch \\ Prof. Dr. Richard Baskerville \\ Georgia State University \\ Atlanta \\ USA \\ Baskerville@acm.org
}

Published online: $2010-08-25$

This article is also available in German in print and via http://www. wirtschaftsinformatik.de: Winter R, Baskerville R (2010) Methodik der Wirtschaftsinformatik. WIRTSCHAFTSINFORMATIK. doi: 10.1007/s11576010-0242-2.

(C) Gabler Verlag 2010
Design science research is the dominant IS research paradigm in the German-speaking countries. A large number of design-oriented researchers can also be found in other, mostly European, IS research communities. Design science research aims at prescriptive learning, i.e. the design and evaluation of innovative, useful, generic problem solutions to important and relevant design problems in organizations. This aim contrasts behavioral IS research that aims at descriptive learning, i.e. the exploration and validation of causal, explanatory, and/or predictive relations between existing IS phenomena.

Both behavioral research and design science research are paralleled by "meta" research. Meta research regards how such social sciences reflect the respective processes, products, roles, etc. This reflection provides guidance for researchers and specifies rigor in the respective approach. Both behavioral research and design science research aim at combining rigor and relevance. In behavioral IS research that is quantitative, metrics such as statistical significance are established as clear and common measures of the rigor in the results, but the relevance of these results is sometimes poor. In contrast, utility for practice is established as a clear and common measure of the relevance of design science research results, but the construction and evaluation rigor of these results is sometimes poor.

Business and information systems engineering addresses a wide range of technoeconomical issues, and thus behavioral research as well as design science research. Regardless of the research approach, business and information systems engineering should be both rigorously conducted and relevant to business practice. From that viewpoint, the rigor of design science research for IS is therefore an important issue. The rigor of design science research has been less well-defined and consequently less commonly accepted than the well expressed and widely accepted rigor in behavioral IS research. While numerous contributions have been made to the justification of design, the typology of artifacts, or specific problem solutions, rigor-related aspects are not sufficiently standardized across the design-oriented research community. One example is the lack of any commonly accepted reference process model. Another example is the debate on the positioning and character of design theories. Although the IS community agrees in general that information systems are comprised of organizational (human) as well as technical (software) components, it is argued whether "pure" organizational artifacts are acceptable outcomes or whether only IT-related artifacts are allowed results. Yet another example for the need to improve rigor in design science research is the lack of commonly accepted, specific evaluation guidelines for different artifact types.

This special issue is devoted to the rigor of the design and engineering of IS artifacts. The call for papers was distributed both through BISE/WI channels and international mailing lists. Interested authors were invited to submit abstracts of their publication projects and to present and discuss their projects at a one-day workshop in St. Gallen in September 2009. This workshop was attended by ten experienced professors and nine author teams. Fifteen submissions were received by the December 2009 deadline, of which 13 were accepted for review. After the first round of reviews, authors of eight submissions were invited to revise and resubmit. After the second round of reviews, one paper was conditionally accepted and four were invited for revision and resubmission. In the third and final round of reviews one paper was accepted and three were conditionally accepted. Overall there were a total of four accepted papers.

We are particularly pleased that this special issue's BISE interview fits our topic perfectly. Jay F. Nunamaker, one of the "founding fathers" of the IS discipline in the United States of America, answers Robert Winter's questions on the direction of the IS discipline, on rigor and publication issues in design-oriented research, as well as on research organization and financing.

Due to space limitations, only three of the four accepted papers can be published in this special issue:

Baskerville and Pries-Heje contribute to the design theory discussion by proposing the focused and simplified concept of an explanatory design theory which relates re- 
quirements and (solution) components for a design problem. They illustrate their proposal by two sets of examples, one from design disciplines in general and one from IS research.

Offermann, Blom, Levina and Bub build on the state-of-the-art of the design theory discussion and propose a specific design theory for methods. For each design theory component, they derive evaluation criteria and present examples of method publications fulfilling the criteria.

Österle and Otto propose a method for Consortium Research, which is supposed to facilitate multilateral collaboration of researchers and practitioners during the research process. The method's design is based on a self-evaluating design process which was carried out over a period of 20 years.

The fourth paper will be published in issue 6/2010: Fettke, Houy and Loos focus on the role of design knowledge in business and information systems engineering. They show that design knowledge is often neglected in design research and they propose foundations to systematically create, validate and reuse design knowledge. They demonstrate their proposal's utility by exemplarily using the event-driven process chain (EPC) technique.

This special issue would not be possible without a lot of hard work by many scholars around the world. We wish to thank all authors, all presenters and discussants at the workshop, and in particular all reviewers - both German-speaking and international for their dedicated efforts in making this special issue a success.

Robert Winter Richard Baskerville 